\title{
Calcium-alginate beads as a formulation for the application of entomopathogenic nematodes to control rootworms
}

\author{
Jinwon $\mathrm{Kim}^{1,2}$ (D) Ivan Hiltpold ${ }^{3,4}$ (D) $\cdot$ Geoffrey Jaffuel $^{1}$ (D) Ilham Sbaiti $^{1}$ (D) Bruce E. Hibbard $^{3,5}$ (D) Ted C. J. Turlings $^{1}$ (D)
}

Received: 18 October 2020 / Revised: 29 January 2021 / Accepted: 6 February 2021 / Published online: 26 February 2021

(c) The Author(s) 2021

\begin{abstract}
Entomopathogenic nematodes (EPN) have great potential as biological control agents against root-feeding insects. They have a rapid and long-lasting mode of action, minimal adverse effects on the environment and can be readily mass-produced. However, they have a relatively short shelf-life and are susceptible to desiccation and UV light. These shortcomings may be overcome by encapsulating EPN in $\mathrm{Ca}^{2+}$-alginate hydrogels, which have been shown to provide a humid and UV protective shelter. Yet, current $\mathrm{Ca}^{2+}$-alginate formulations do not keep EPN vigorous and infectious for a prolonged period of time and do not allow for their controlled release upon application. Here, we introduce solid $\mathrm{Ca}^{2+}$-alginate beads which we supplemented with glycerol to better retain the EPN during storage and to ensure a steady release when applied in soil. Glycerolinduced metabolic arrest in EPN (Heterorhabditis bacteriophora) resulting in quiescence and total retainment of EPN when added to beads made with $0.5 \%$ sodium alginate and $2 \% \mathrm{CaCl}_{2} \cdot 2 \mathrm{H}_{2} \mathrm{O}$ solutions. More than 4,000 EPN could be embedded in a single 4-5-mm diameter bead, and quiescence could be broken by adding water, after which the EPN readily emerged from the beads. In a field trial, the EPN beads were as effective in reducing root damage by the western corn rootworm (WCR, Diabrotica virgifera virgifera) as EPN that were applied in water. Although further improvements are desirable, we conclude that $\mathrm{Ca}^{2+}$-alginate beads can provide an effective and practical way to apply EPN for the control of WCR larvae.
\end{abstract}

Keywords Alginate beads $\cdot$ Entomopathogenic nematodes $\cdot$ Maize $\cdot$ Rootworms $\cdot$ Root pest control $\cdot$ Glycerol-induced quiescence

\section{Key Message}

- The full potential of entomopathogenic nematodes (EPN) as biological control agents has yet to be achieved.

Communicated by Nicolas Desneux.

Ted C. J. Turlings

ted.turlings@unine.ch

1 FARCE Laboratory, Institute of Biology, University of Neuchâtel, Neuchâtel, Switzerland

2 Seoul Viosys Co. Ltd., Ansan, Gyeonggi-do, Republic of Korea

3 Division of Plant Sciences, University of Missouri, Columbia, MO, USA

4 Agroscope, Route de Duillier 50, P.O. Box 1012, 1260 Nyon 1, Switzerland

5 USDA-ARS, Plant Genetics Research Unit, University of Missouri, Columbia, MO, USA
- Main obstacles include short shelf-life, susceptibility to desiccation and UV light, and untimely release.

- We formulated an alginate bead supplemented with glycerol to induce EPN quiescence.

- The beads can retain more than 4,000 nematodes each, and quiescence can readily be broken by adding water.

- In a field trial, EPN beads effectively reduced root damage by the western corn rootworm.

\section{Introduction}

Entomopathogenic nematodes (EPN) have been shown to be highly effective biological control agents with unique advantages that chemical and other biological pesticides do not have. EPN can kill insect pests within days after infection; tens to hundreds of thousands of new EPN may be produced from a single infested insect host and travel to infect new hosts, thus theoretically allowing them to persist in the field throughout the growing season (Kurtz et al. 
2007; Lewis et al. 2006). Moreover, EPN are compatible and can be co-applied with other biological pesticides and agrochemicals (Grewal 2002; Imperiali et al. 2017; Rovesti and Deseö 1990; Shapiro-Ilan et al. 2012; Shapiro-Ilan et al. 2004) and have minimal undesirable effects such as soil contamination, bioaccumulation or adverse effects on non-target organisms (Bathon 1996; Lewis et al. 2006; Peters 1996). Despite these advantages, EPN application in large-scale farming is still rare because of some critical obstacles such as higher production cost as compared to synthetic chemical pesticides and the vulnerability of EPN to environmental factors (Georgis et al. 2006).

The free-living, foraging infectious juveniles (IJs) do not feed and use their stored energy reserves until they find an insect host. Therefore, the viability and infectivity of IJs decrease over time as energy reserves are depleted. This limits the shelf-life of EPN products to maximally a few months even when properly stored (Grewal 2002; Koppenhöfer 2007; Shapiro-Ilan et al. 2006). They are also highly susceptible to UV radiation, heat and desiccation; therefore, many EPN die soon after application due to exposure to air and sunlight, and only a tiny fraction will reach target hosts (Gaugler et al. 1997). In addition, they are mostly applied in liquid formulations that require proper agitation in storage tanks to prevent the EPN from settling down at the bottom (Shapiro-Ilan et al. 2012).

Considerable research effort has gone into the development of suitable EPN formulations with the aim to prolong storage, easy transport and handling, efficient application and enhanced post-application survival (Cruz-Martínez et al. 2017; Grewal 2002; Shapiro-Ilan et al. 2006). For instance, water-dispersible granules have been made of mixtures of clays, silica, cellulose, lignin and starch. When mixed with EPN, the granules cause desiccation stress, so-called anhydrobiosis, and thereby induce quiescence in EPN, which significantly reduces metabolic rate and prolongs EPN longevity with minimum loss of infectivity even at room temperature (Grewal 2000a, 2000b; Matadamas-Ortiz et al. 2014). Another promising formulation strategy is the direct application of EPN-infested insect cadavers, which can be buried directly in soil. Most fresh and infectious EPN are released from the cadavers into the rhizosphere just a few days after application (Del Valle et al. 2008; Jansson et al. 1993). EPN-infested cadavers, however, are fragile and may rupture during transport and handling. Potting soil premixed with EPN-infested cadavers and a tape-formulation of dry cadavers have been developed to improve handling, but still suffer from limited shelf-life and reduced infectivity of EPN, respectively (Deol et al. 2011; Zhu et al. 2011).

Alginate, a comparatively cheap linear polymer comprising continuous or alternating $1 \rightarrow 4$ linked units of $\beta$-Dmannuronic acid and $\alpha$-L-guluronic acid, readily cross-links with divalent cations such as $\mathrm{Ca}^{2+}$ to form stable hydrogels
(Donati et al. 2005; King 1982). Due to their hydrophilic, biocompatible and biodegradable characteristics alginate gels have been widely studied to be used as a formulation to deliver drugs, viable cells or microorganisms for medical purposes (Dong et al. 2013; Hoffman 2012; Tønnesen and Karlsen 2002), biofertilizer (i.e., Rhizobium) and biomicrobial pesticides (Bashan 1998; John et al. 2011; Schoebitz et al. 2013). Alginate hydrogels also show promise for EPN formulation as they provide protection from desiccation, UV light and natural enemies. Several reports describe $\mathrm{Ca}^{2+}$-alginate-based EPN formulations (Hiltpold et al. 2012; Kaya et al. 1987; Kaya and Nelsen 1985; Kim et al. 2015; Navon et al. 1998, 2002; Renn 1995), but further improvements are needed to ensure EPN viability and infectivity and to control the release of the nematodes (Kary et al. 2018).

We previously showed that producing of $\mathrm{Ca}^{2+}$-alginate EPN capsules (or "hollow beads" as defined by Vemmer and Patel (2013)) (Fig. 1) at $4{ }^{\circ} \mathrm{C}$ significantly enhanced retainment of EPN as compared to capsules produced at room temperature (Kim et al. 2015). However, a considerable number of encapsulated EPN still escaped from the capsules during a 7-day storage period at room temperature and their viability gradually decreased over time probably because the alginate polymer acts as an oxygen barrier (Sabra et al. 2000). Furthermore, the release of EPN from the capsules after application in the soil was poor.

Here, we present an improved version of an alginatebased EPN formulation. We used alginate beads ("solid spheres" as defined by Vemmer and Patel (2013)) instead of capsules (Fig. 1). Previously reported EPN beads produced from $2 \%$ alginate solution dropped into $\mathrm{CaCl}_{2} \cdot 2 \mathrm{H}_{2} \mathrm{O}$ or $\mathrm{CaCO}_{3}$ solution were found not to be practical because EPN were not able to escape unless the beads were damaged by insect biting into them or after germination of co-encapsulated tomato seeds (Kaya et al. 1987; Kaya and Nelsen 1985; Navon et al. 1998; Renn 1995). Moreover, the EPN in these formulations were continuously moving, which consumes energy reserves, leading to early mortality and preventing long-term storage. Chen and Glazer (2005) were the first to propose that these problems can be readily solved by inducing EPN quiescence with the addition of glycerol to the solution before encapsulation. The efficacy of this method, which we adopted for the current study, was recently validated by Kary et al. $(2017,2018)$, who also confirmed that EPN quiescence can be simply broken by diluting the glycerol with water. Here, we explored a novel way of making alginate beads that can contain large numbers of EPN and that can be mass-produced at low cost.

Particularly important for the success of alginate-based EPN formulations is good control over the EPN encapsulation process. Moreover, the EPN should remain healthy and be retained during storage, whereas they should be readily released when applied in soil. For this purpose, we 


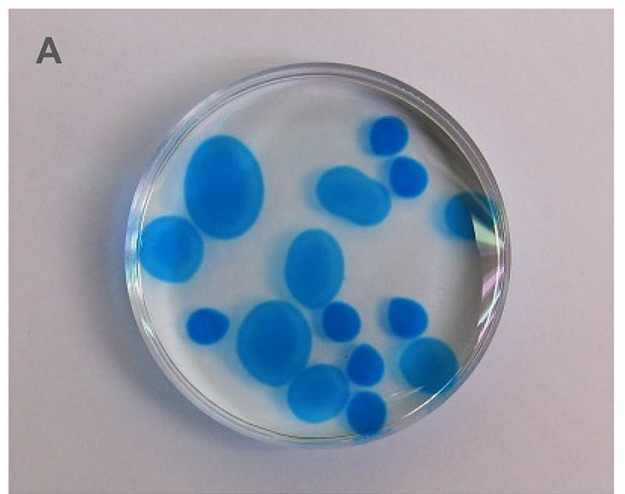

Fig. $1 \mathrm{Ca}^{2+}$-alginate capsules $\mathbf{a}$ and beads $\mathbf{b}$ inside a petri dish (diam $60 \mathrm{~mm}$ ). The capsules are of different sizes because they were made with different numbers of droplets of a $\mathrm{CaCl}_{2} \cdot 2 \mathrm{H}_{2} \mathrm{O}$ solution applied to a sodium alginate solution (Kim et al. 2015). Note that each capsule shell surrounds a liquid core. In contrast, the $\mathrm{Ca}^{2+}$-alginate beads were solid and were produced by dropping single droplets of sodium

screened a series of different concentrations of alginate and $\mathrm{CaCl}_{2} \cdot 2 \mathrm{H}_{2} \mathrm{O}$ to determine which combination would allow the optimal EPN release within $24 \mathrm{~h}$. In addition, we increased the number of encapsulated EPN to more than 4,000 per bead, instead of 100-300 as previously reported (Hiltpold et al. 2012; Kaya et al. 1987; Kaya and Nelsen 1985; Kim et al. 2015; Navon et al. 1998, 2002; Renn 1995). With these modifications, we were able to manufacture beads for long-term storage at room temperature without significant loss of EPN infectiousness and with highly effective release of thousands of EPN per bead after soil application.

Finally, we successfully tested the newly developed EPN beads under realistic field conditions against Diabrotica virgifera virgifera, the western corn rootworm (WCR), a univoltine chrysomelid beetle, whose larvae feed on maize roots and can cause tremendous yield losses (Chiang et al. 1980; Godfrey et al. 1993; Gray et al. 2009).

\section{Materials and methods}

\section{Nematodes, insects and chemicals}

Infectious juveniles of Heterorhabditis bacteriophora Poinar (Rhabditida: Heterorhabditidae), which have been repeatedly reported to be effective against WCR (Kurtz et al. 2009; Toepfer et al. 2005, 2008), were kindly provided by Andermatt Biocontrol AG (Grossdietwil, Switzerland) and used throughout this study. The correct taxonomic species assignment of this nematode was recently confirmed by Dr. Ricardo Machado (University of Neuchâtel, personal communication). The colony of $H$. bacteriophora was maintained on waxmoth (Galleria mellonella L.) larvae that were purchased from a local fishing shop as previously described

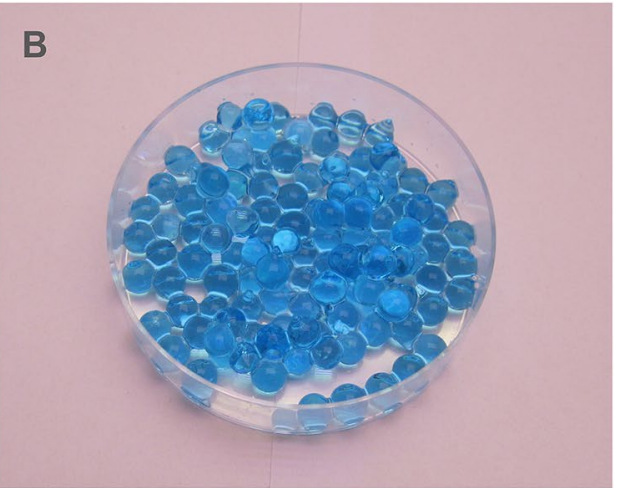

alginate solution into a $\mathrm{CaCl}_{2} \cdot 2 \mathrm{H}_{2} \mathrm{O}$ solution. All beads are of the same size because for each drop cross-linking occurs immediately due to excessive $\mathrm{Ca}^{2+}$ ions, preventing the formation of a liquid core. Figure 1a was reused from Kim et al. 2015 with permission of the editor

(Kim et al. 2015). Newly emerged IJs from waxmoth cadavers were collected in a White trap (White 1927) and stored at a density lower than 1,000 EPN per 1-ml water in an angled-neck cell culture flask (ThermoScientific, Reinach, Switzerland), for a maximum of five days at $12{ }^{\circ} \mathrm{C}$. IJs were examined under the microscope and used for further experiments only when all IJs were alive and active in the flask.

A strain of non-diapausing western corn rootworms (WCR) Diabrotica virgifera virgifera (Coleoptera: Chrysomelidae) were used for the field experiment. The strain was originally obtained from the US Department of Agriculture-Agricultural Research Service (USDA-ARS) North Central Agricultural Research Laboratory in Brookings (South Dakota, USA) and maintained in the USDAARS Plant Genetics Research Unit in Columbia (Missouri, USA).

Sodium alginate, Gluco ${ }^{\circledR}$ (a mixture of calcium salts of lactic and gluconic acids) and xanthan were purchased from Solé Graells (Barcelona, Spain), $\mathrm{CaCl}_{2} \cdot 2 \mathrm{H}_{2} \mathrm{O}$ from Fluka (Buchs, Switzerland), glycerol from Sigma-Aldrich (St. Louis, MO, USA) and blue food dye from Schneitter (Neuchâtel, Switzerland). We used deionized water for all formulations.

\section{Evaluation of glycerol-induced quiescence of EPN in alginate capsules}

Glycerol-containing $\mathrm{Ca}^{2+}$-alginate EPN capsules were produced at room temperature as described by Kim et al. (2015) except that in all solutions a concentration of $18 \%$ $(\mathrm{v} / \mathrm{v})$ glycerol was used. An alginate-glycerol solution $(0.5 \%$ of alginate, $\mathrm{w} / \mathrm{v} ; 18 \%$ glycerol, $\mathrm{v} / \mathrm{v})$ and a mixture of Gluco ${ }^{\circledR}(2 \%, w / v)$, xanthan $(0.4 \%, w / v)$, glycerol $(18 \%$, $\mathrm{v} / \mathrm{v})$ and blue dye $(0.05 \%, \mathrm{v} / \mathrm{v})$ was prepared and degassed 
in vacuo. IJs of $H$. bacteriophora were harvested from water in cell culture flasks onto a Whatman filter paper $(\varnothing$ $60 \mathrm{~mm}$ ) using a Buchner funnel and were re-suspended in the mixture of Gluco®, xanthan, glycerol and blue dye in a 15-ml Falcon tube at a concentration that ensured that each capsule would contain ca. 200 EPN. The solution was stored at $12{ }^{\circ} \mathrm{C}$ overnight and the next morning, after EPN quiescence was confirmed under an optical microscope (SZ40, Olympus, Tokyo, Japan), the EPN-containing mixture of Gluco®, xanthan, glycerol and blue dye was loaded in a 1-ml disposable syringe (Norm-Ject ${ }^{\circledR}$, Henk-Sass Wolf GmbH, Tuttlingen, Germany) from which the barrel had been cut off, resulting in an orifice of $\varnothing 4.5 \mathrm{~mm}$. Droplets of ca. $90 \mu \mathrm{l}$ of the mixture were dropped into $20 \mathrm{ml}$ of alginate-glycerol solution in a 50-ml beaker and gently and continually stirred for $20 \mathrm{~min}$. The EPN capsules that were formed were rinsed in $18 \%$ glycerol, and each stored in a $\emptyset 60-\mathrm{mm}$ disposable petri dish half immersed in $18 \%$ glycerol solution at $24{ }^{\circ} \mathrm{C}$ in the dark. As controls, we also produced ten glycerol-free EPN capsules, which were stored under the same conditions, but immersed in water without glycerol. After a week, the number of EPN that had escaped from each type of capsules was counted $(n=10)$.

\section{Production of EPN beads containing $18 \%$ glycerol}

Glycerol-containing $\mathrm{Ca}^{2+}$-alginate beads were manufactured according to the modified method of Kaya and Nelsen (1985). Solutions of alginate-glycerol $(0.5 \%$ sodium alginate, w/v; $18 \%$ glycerol, v/v; $0.05 \%$ blue dye, v/v; $0.075 \%$ formaldehyde, v/v) and $\mathrm{CaCl}_{2}$-glycerol $\left(2 \% \mathrm{CaCl}_{2} \cdot 2 \mathrm{H}_{2} \mathrm{O}\right.$, $\mathrm{w} / \mathrm{v} ; 18 \%$ glycerol, v/v) were prepared and degassed in vacuo. IJs of $H$. bacteriophora were harvested from water in cell culture flasks onto a Whatman filter paper $(\varnothing 60 \mathrm{~mm})$ using a Buchner funnel, re-suspended in alginate-glycerol solution and stored at $12{ }^{\circ} \mathrm{C}$ overnight. The next morning, after quiescence of EPN in the alginate-glycerol solution was confirmed under an optical microscope (SZ40, Olympus, Tokyo, Japan), the EPN-alginate-glycerol solution was dripped from a 1-ml disposable syringe (Norm-Ject ${ }^{\circledR}$, Henk-Sass Wolf GmbH, Tuttlingen, Germany) into a container with $\mathrm{CaCl}_{2}$-glycerol solution. Up to 100 droplets per $100 \mathrm{ml}$ of $\mathrm{CaCl}_{2}$-glycerol solution were added, and $10 \mathrm{~min}$ later, $\mathrm{Ca}^{2+}$-alginate beads were collected. The volume of each droplet of alginate-glycerol solution was $85.3 \pm 3 \mu \mathrm{l}$ on average $(n=20)$. Different from the capsules, the alginate beads floated on the surface and did not stick to each other in the solution. Stirring of the solution during bead formation was therefore not necessary and it was possible to produce as many beads in a single container as the solution surface allowed. Glycerol-free EPN beads were produced under the same conditions.

\section{Comparing different concentrations of sodium alginate and $\mathrm{CaCl}_{2} \cdot 2 \mathrm{H}_{2} \mathrm{O}$ to optimize release of EPN from the beads}

EPN were harvested from water, re-suspended in a series of sodium alginate solutions at concentrations ranging from 0.5 to $2 \%(\mathrm{w} / \mathrm{v})$ and dripped into a series of $\mathrm{CaCl}_{2} \cdot 2 \mathrm{H}_{2} \mathrm{O}$ solutions at concentrations ranging from 0.3 to $2 \%(\mathrm{w} / \mathrm{v})$. Approximately 200 EPN were encapsulated in each bead. EPN beads were individually placed, half immersed in water, in a $\varnothing 60-\mathrm{mm}$ petri dish and stored at $24{ }^{\circ} \mathrm{C}$ in the dark. After a week, the number of EPN that escaped from each bead was counted under an optical microscope $(n=24)$.

\section{EPN escape from $\mathrm{Ca}^{2+}$-alginate beads containing different numbers of EPN}

We also tested whether the nematodes indeed escape from the beads when their quiescence is broken by adding water. Twelve $\mathrm{Ca}^{2+}$-alginate beads containing on average 172, 430, $859,1,718$ and 4,295 EPN were produced under the influence of $18 \%$ glycerol as described above (named simply, $0.2 \mathrm{~K}, 0.5 \mathrm{~K}, 1 \mathrm{~K}, 2 \mathrm{~K}$ and $4 \mathrm{~K}$ EPN beads, respectively) and individually stored in a 3-ml glass vial half immersed in $300 \mu \mathrm{l}$ of water with $18 \%$ glycerol. The vials were kept in a 500-ml plastic container at $24{ }^{\circ} \mathrm{C}$ in the dark. After a week, each bead was transferred into a $20-\mathrm{ml}$ cell culture flask (ThermoScientific, Reinach, Switzerland) containing $5 \mathrm{ml}$ of water in order to break quiescence. An additional week later, all the EPN that were liberated from each bead were individually counted under an optical microscope $(n=10$ per EPN dose).

\section{Determination of the conversion rate of $\mathrm{Ca}^{2+}$ ions in $\mathrm{a} \mathrm{CaCl}_{2} \cdot 2 \mathrm{H}_{2} \mathrm{O}$ solution during the production of $\mathrm{Ca}^{2+}$-alginate beads}

Different from $\mathrm{Ca}^{2+}$-alginate capsules that stick together and sink to the bottom in the sodium alginate solution (Kim et al. 2015), the EPN beads described here float at the surface of $\mathrm{CaCl}_{2} \cdot 2 \mathrm{H}_{2} \mathrm{O}$ solution and do not stick together, making the procedure highly suitable for automated mass-production. The production cycle can be continuously repeated by dropping EPN-containing sodium alginate solution into $\mathrm{CaCl}_{2} \cdot 2 \mathrm{H}_{2} \mathrm{O}$ solution, repeatedly harvesting the beads and adding $\mathrm{CaCl}_{2} \cdot 2 \mathrm{H}_{2} \mathrm{O}$ to the solution to compensate for the consumed $\mathrm{Ca}^{2+}$ ions. In order to determine how many of the $\mathrm{Ca}^{2+}$ ions are consumed during bead production, $100 \mathrm{ml}$ of $2 \% \mathrm{CaCl}_{2} \cdot 2 \mathrm{H}_{2} \mathrm{O}$ solution was used to produce 100,200 or $300 \mathrm{Ca}^{2+}$-alginate beads in a $500-\mathrm{ml}$ plastic container and 
the concentration of remaining $\mathrm{Ca}^{2+}$ ions remaining in the solution was then determined. It was possible to produce 100 beads in $100 \mathrm{ml}$ of $2 \% \mathrm{CaCl}_{2} \cdot 2 \mathrm{H}_{2} \mathrm{O}$ solution in a given container, and we produced more beads in the following three rounds of 100 beads. The produced beads were removed after each round using a sieve, and the remaining $\mathrm{CaCl}_{2} \cdot 2 \mathrm{H}_{2} \mathrm{O}$ solution was re-used for the next round. After bead production, for each round, the remaining $\mathrm{Ca}^{2+}$ ions were quantified using inductively coupled plasma atomic emission spectroscopy (ICP-AES; OPTIMA 3300 DV with AS-90 autosampler, Perkin Elmer, Waltham, MA, USA) at the Neuchâtel Platform of Analytical Chemistry (University of Neuchâtel, Switzerland). For the ICP-AES analyses, we used argon 5.0, nitrogen 5.0 and compressed air at $15 \mathrm{ml} \mathrm{min}^{-1}$ for plasma, $0.5 \mathrm{ml} \mathrm{min}^{-1}$ auxiliary and $0.65 \mathrm{ml} \mathrm{min}^{-1}$ for nebulizer, respectively. Samples were injected at $1.5 \mathrm{ml} \mathrm{min}{ }^{-1}$. The concentration of $\mathrm{Ca}^{2+}$ ions in the samples was determined using the PlasmaCAL-SCP33MS standard solution (SCP Science, Courtaboeuf, France) prepared in $2 \% \mathrm{HNO}_{3}$. For comparison, concentration of $\mathrm{Ca}^{2+}$ ions was also measured in $2 \%$ and $1.5 \% \mathrm{CaCl}_{2} \cdot 2 \mathrm{H}_{2} \mathrm{O}$ solutions. One ppm manganese solution in $2 \% \mathrm{HNO}_{3}$ (Perkin Elmer, Waltham, MA, USA) was measured prior to each run to ensure overall suitability of the system.

\section{Field testing of glycerol beads to control WCR}

A series of field experiments to compare the efficacy of EPN beads produced as described above were carried out in a maize field at the Bradford Research Center of University of Missouri (Columbia, MO, USA). Seeds of the WCR-susceptible maize cultivar P1420Hr CRM 114 (source: Pioneer M3PRI 11,030-N; Size: F14; DuPont Pioneer, Des Moines, IA, USA) were planted in the field on May 16th, 2014, and about $800 \mathrm{WCR}$ eggs in $0.01 \%$ agar solution were applied in the soil next to each plant two weeks later. Heterorhabditis bacteriophora was purchased from Arbico Organics (Oro Valley, AZ, USA).

EPN beads were freshly made as described above and were applied in the soil (i) on May 22nd when the first maize seedlings started to show and WCR larvae had not yet hatched from the eggs (early application) or (ii) on June 11 th in the middle of the growing season when WCR larvae were feeding on the roots (late application) or (iii) on the both dates (early and late application). In other plots, we used a conventional application of EPN in water solution on the same two dates of early and late applications. Empty beads, as the bead control, were also applied twice on the same dates. The blank plots received neither WCR eggs nor EPN, and the WCR control plots were treated only with WCR eggs.

Each of seven treatments was replicated 16 times in a randomized complete block design, using 16 rows of maize within which all treatments were randomly distributed. Maize plants were planted $15 \mathrm{~cm}$ apart from each other in a row, with $75 \mathrm{~cm}$ between rows. Nine plants in a row formed a plot and received the same treatment; hence, each row comprised seven plots, which were randomly assigned to each of the seven treatments. Plots were buffered with five plants between plots within the row, and the treated rows were buffered with three untreated rows of maize plants in between. On all sides, the field was surrounded by at least thirty untreated rows of maize.

To apply each treatment, two holes of about $1 \mathrm{~cm}$ in diameter and $20 \mathrm{~cm}$ deep were made about $15 \mathrm{~cm}$ away from a plant and on both sides of and perpendicularly to the plant row. For the application of the EPN solution, the solution was prepared fresh by adding EPN to water at a concentration of $1,000 \mathrm{ml}^{-1}, 15 \mathrm{ml}$ of which was applied into each of two holes with a pipette (representing 30,000 EPN per plant). During application, the solution was agitated frequently to prevent EPN settlement at the bottom of the container. For the bead application, $4 \mathrm{~K}$ EPN beads, as well as the control beads were produced with $18 \%$ glycerol as described above a day before application, and ten beads were dropped into the two holes, five beads per hole (assuming an escape rate of $80 \%$, Fig. 2, this represented about 32,000 per plant). The holes were re-filled with soil after application of the solution or beads.

Maize plants from all plots were uprooted on July $10^{\text {th }}$. Soil on roots was washed off with water, and root damage by WCR was evaluated according to the $0-3$ node injury scale (Oleson et al. 2005).

\section{Statistical analyses}

All the data presented in this manuscript were tested with SAS (SAS 9.3, SAS Inc.) for normality and equal variances, and means were tested for significant differences using oneway ANOVA test or Kruskal-Wallis test, accordingly. Multiple comparisons of data were conducted using post hoc Tukey's test when $p<0.05$.

\section{Results}

\section{Glycerol-induced quiescence of EPN}

After overnight treatment in an $18 \%$ glycerol solution, all EPN were found dormant the next morning. When encapsulated as described by Kim et al. (2015) and stored partially immersed in a $18 \%$ glycerol solution at room temperature for a week, not a single EPN was found outside of the capsules. Yet, when the glycerol was diluted by adding water almost all EPN became active and left the capsules. However, from capsules made under the same conditions but without 


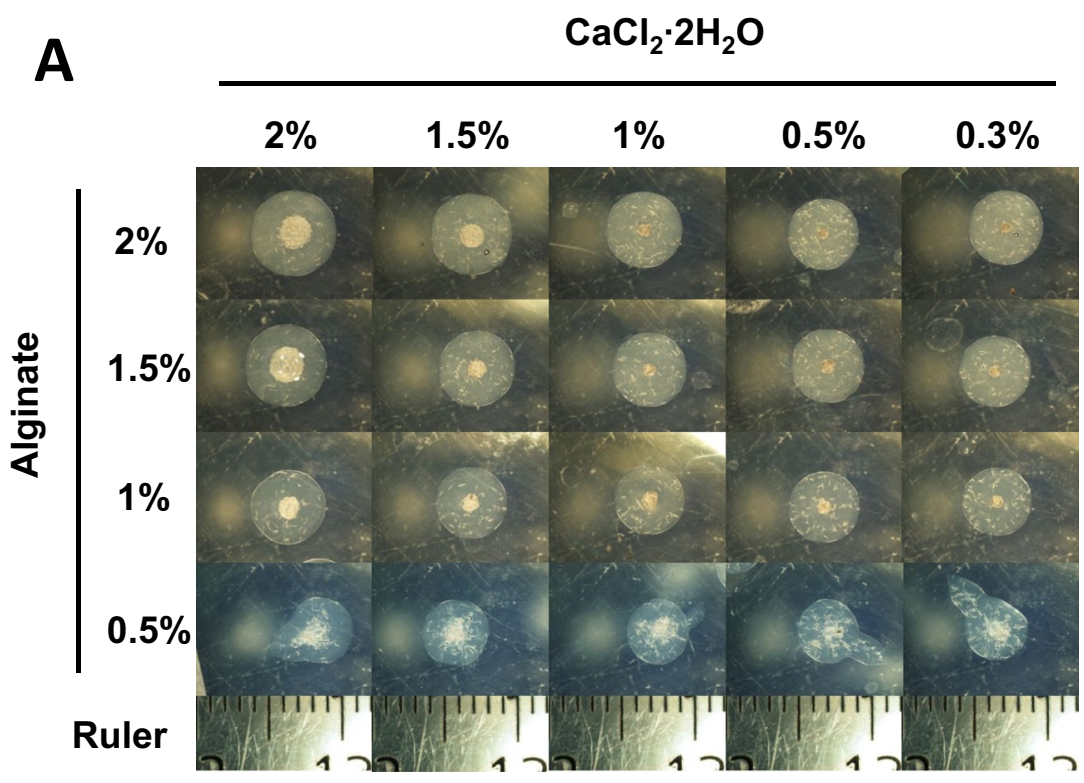

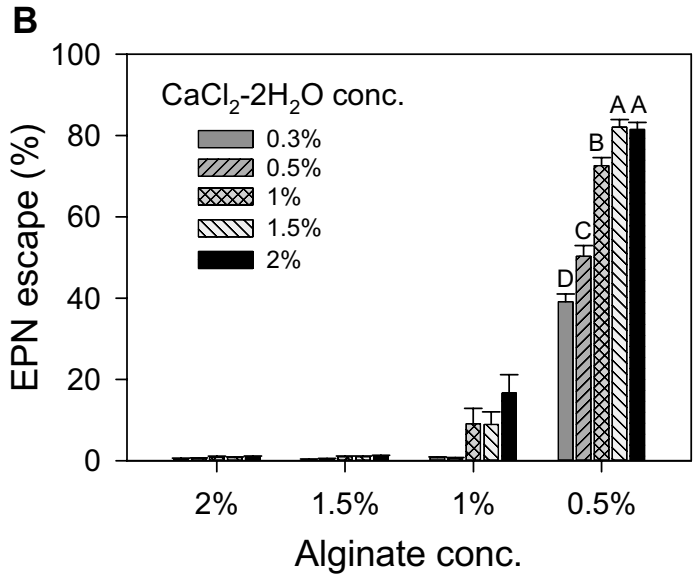

Fig. 2 Beads made with different concentrations of sodium alginate and $\mathrm{CaCl}_{2} \cdot 2 \mathrm{H}_{2} \mathrm{O}$ without quiescence-inducing glycerol. a Photographs taken right after bead production from different concentration combinations. Notice the different accumulations of EPN at the center of the beads and the different number of EPN that were caught in the outer part. The smaller markings on the ruler are $1 \mathrm{~mm}$ apart. b The number of EPN that escaped from each bead was counted a week after the beads were formed and the data from beads formed

$18 \%$ glycerol, a significantly number of EPN were found to escape prematurely $(37.7 \pm 13.2 \%$ vs. $0 \%$, mean $\pm \mathrm{SE}$, Kruskal-Wallis test; $\chi^{2}=6.1688, p=0.013, d f=1, n=10$, $N=20$ ). When we embedded the EPN in solid alginate beads with $18 \%$ glycerol, the EPN were also completely retained and quiescence was maintained until the glycerol was diluted with an excess of water.

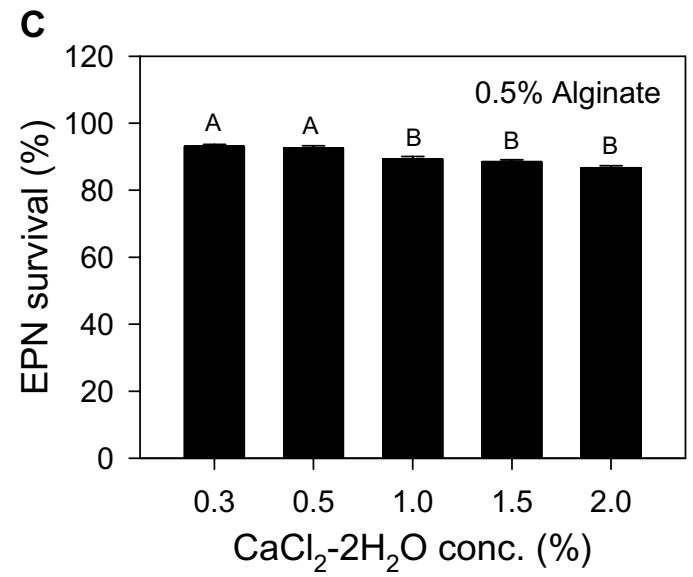

with $0.5 \%$ alginate concentration are shown in the graph (mean \pm SE; Kruskal-Wallis test followed by post hoc Tukey's test; $\chi^{2}=89.9519$, $p<0.0001, d f=4, n=24, N=120)$ and $\mathbf{c}$ the number of dead EPN from the beads formed with $0.5 \%$ alginate concentration was also counted to obtain survivorship values (mean \pm SE; ANOVA test followed by post hoc Tukey's test; $F_{4,115}=15.5, p<0.0001, d f=4$, $n=24, N=120)$. Bars represent SEM, and capital letters indicate statistical differences between treatments

\section{Escape of EPN from $\mathrm{Ca}^{2+}$-alginate capsules and beads}

Alginate solutions of concentrations higher than $2 \%$ were too thick to handle. Also, beads were not properly formed when the concentrations of sodium alginate and $\mathrm{CaCl}_{2} \cdot 2 \mathrm{H}_{2} \mathrm{O}$ solutions were below $0.5 \%$ and $0.3 \%$, respectively. We therefore manufactured alginate beads (with about $200 \mathrm{EPN}$ ) from solutions with concentrations of sodium alginate and $\mathrm{CaCl}_{2} \cdot 2 \mathrm{H}_{2} \mathrm{O}$ ranging from 0.5 to $2.0 \%$ and 0.3 to $2.0 \%$, respectively, initially without glycerol. Beads formed from 
$0.5 \%$ of sodium alginate solution in $\mathrm{CaCl}_{2} \cdot 2 \mathrm{H}_{2} \mathrm{O}$ solution of any concentrations between 0.3 and $2.0 \%$ were not spherical as shown in Fig. 2, but still sufficiently firm for easy handling and became almost spherical after more practice in making them. We did not use $\mathrm{CaCl}_{2} \cdot 2 \mathrm{H}_{2} \mathrm{O}$ solution over $2 \%$ to avoid salinity stress. Photographs of EPN beads were taken right after production, and a week later, the number of EPN that had escaped from each bead was counted (Fig. 2).

The photographs in Fig. 2 show how the EPN behave during bead formation. After a droplet of sodium alginate solution is dropped into the $\mathrm{CaCl}_{2} \cdot 2 \mathrm{H}_{2} \mathrm{O}$ solution, cross-linking of alginate polymers by $\mathrm{Ca}^{2+}$ ions starts right away at the boundary of the two solutions and the $\mathrm{Ca}^{2+}$-alginate bead matrix grows inward. In general, a small number of EPN were found trapped in the matrix, but the majority moved to the center. Judging from the decreasing number of EPN in the center and the increasing number embedded within the bead matrix at the higher concentrations of $\mathrm{CaCl}_{2} \cdot 2 \mathrm{H}_{2} \mathrm{O}$, the $\mathrm{Ca}^{2+}$-alginate cross-linking occurred more rapidly when the concentrations of $\mathrm{CaCl}_{2} \cdot 2 \mathrm{H}_{2} \mathrm{O}$ were higher (Fig. 2a).

When EPN beads were formed with $1.5 \%$ or $2.0 \%$ sodium alginate solutions, less than $1 \%$ of the encapsulated EPN escaped from the beads, irrespective of the concentrations of $\mathrm{CaCl}_{2} \cdot 2 \mathrm{H}_{2} \mathrm{O}$ (Fig. 2b). Escape rates were significantly higher when beads were formed by dropping droplets of $0.5 \%$ sodium alginate solution into a $\mathrm{CaCl}_{2} \cdot 2 \mathrm{H}_{2} \mathrm{O}$ solution, and the highest EPN escape rate of about $82 \%$ was achieved when EPN beads were produced with a $0.5 \%$ sodium alginate solution combined with a $1.5 \%$ or $2.0 \% \mathrm{CaCl}_{2} \cdot 2 \mathrm{H}_{2} \mathrm{O}$ solution (Kruskal-Wallis test followed by post hoc Tukey's test; $\chi^{2}=89.9519, p<0.0001, d f=4, n=24, N=120$ ) (Fig. 2b). Survival of EPN from beads made with a $0.5 \%$ sodium alginate solution decreased with increased concentrations of $\mathrm{CaCl}_{2} \cdot 2 \mathrm{H}_{2} \mathrm{O}$, but remained still very high, ranging from 86.7 to $93.0 \%$ (ANOVA test followed by post hoc Tukey's test; $F_{4,115}=15.5, p<0.0001, n=24, N=120$ ) (Fig. 2c). Because calcium ions in the $\mathrm{CaCl}_{2} \cdot 2 \mathrm{H}_{2} \mathrm{O}$ solution are continuously consumed when cross-linking alginate polymers, we selected $2.0 \%$ instead of $1.5 \%$ of $\mathrm{CaCl}_{2} \cdot 2 \mathrm{H}_{2} \mathrm{O}$ for the following experiments to have more $\mathrm{Ca}^{2+}$ ions available for cross-linking.

\section{Escape rates from $\mathrm{Ca}^{2+}$-alginate beads with different numbers of EPN}

About $82 \%$ of the EPN escaped from beads that had been manufactured without glycerol, as described above. In contrast, when we added $18 \%$ glycerol to similar beads, only half of the EPN $(48.1 \pm 1.9 \%$, mean \pm SE, $n=24)$ managed to escape after the beads were placed in water, prompting us to try to find a way to enhance the escape rate. We first tested if this could be achieved with larger numbers of EPN per bead, expecting that the higher numbers of EPN would facilitate movement through the matrix.

We prepared $0.5 \%$ alginate solutions containing $18 \%$ glycerol, $0.05 \%$ blue dye, $0.075 \%$ formaldehyde with 200 , $500,1000,2000$ or $4000 \mathrm{EPN}$ per $100 \mu \mathrm{l}$. There was no significant difference in droplet size of solutions containing different numbers of EPN (ANOVA; $F_{4,45}=1.957$, $p=0.117, n=10, N=50$ ), and the mean volume of a droplet of all the EPN-alginate solutions was $85.9 \pm 0.7 \mu \mathrm{l}$ (mean $\pm \mathrm{SE}$ ). Thus, the number of EPN in the beads manufactured from these solutions was estimated to be 172, 430, 859,1718 and 4295 , which we simply refer to as $0.2 \mathrm{~K}$, $0.5 \mathrm{~K}, 1 \mathrm{~K}, 2 \mathrm{~K}$ and $4 \mathrm{~K}$ EPN beads, respectively. Only $0.17,0.37,0.33,0.51$ and $0.52 \%$ of the EPN escaped on average from these beads, respectively, during the 7 days that the beads were stored in the presence of glycerol. The $4 \mathrm{~K}$ EPN beads were completely filled with EPN, but the beads still maintained a solid and round form (Fig. 3).

After 7 days of storage at room temperature, glycerolinduced quiescence was broken by adding water, allowing EPN escape for the next 7 days. Then, EPN that had escaped out of each bead were counted as dead or alive under a microscope (Table 1). Almost $80 \%$ of the EPN escaped from the $0.2 \mathrm{~K}$ EPN beads, and the escape rate increased with the number of EPN per bead, reaching almost $90 \%$ for the $4 \mathrm{~K} \mathrm{EPN}$ beads. Moreover, survival rate was very high (98.1-99.5\%). Based on these results, $4 \mathrm{~K}$ EPN beads produced with $0.5 \%$ alginate and $2 \%$ $\mathrm{CaCl}_{2} \cdot 2 \mathrm{H}_{2} \mathrm{O}$ solutions with the addition of $18 \%$ glycerol were used for the field experiment to test their efficacy in controlling WCR (Table 2).

\section{Expenditure of $\mathrm{Ca}^{2+}$ ions in production of $\mathrm{Ca}^{2+}$-alginate beads}

Different from $\mathrm{Ca}^{2+}$-alginate capsules (Hiltpold et al. 2012; Kim et al. 2015), beads can be produced as many as the surface area of the formulation container allows because the $\mathrm{Ca}^{2+}$-alginate matrix grows inward, and therefore, $\mathrm{Ca}^{2+}$-alginate beads do not stick to each other. This should simplify mass-production as long as sufficient $\mathrm{Ca}^{2+}$ ions are added to the solution. We determined how much $\mathrm{Ca}^{2+}$ ions participated in the formation of 100 $\mathrm{Ca}^{2+}$-alginate beads and consumed from $100 \mathrm{ml}$ of $2 \%$ $\mathrm{CaCl}_{2} \cdot 2 \mathrm{H}_{2} \mathrm{O}$ solution using inductively coupled plasma atomic emission spectroscopy (ICP-AES). The concentration of $\mathrm{Ca}^{2+}$ ions in $1.5 \%$ and $2 \% \mathrm{CaCl}_{2} \cdot 2 \mathrm{H}_{2} \mathrm{O}$ solutions was $3.78 \mathrm{mg} \mathrm{ml}^{-1}$ and $5.21 \mathrm{mg} \mathrm{ml}^{-1}$, respectively. After the first production of $100 \mathrm{Ca}^{2+}$-alginate beads in the $2 \% \mathrm{CaCl}_{2} \cdot 2 \mathrm{H}_{2} \mathrm{O}$ solution, the concentration of $\mathrm{Ca}^{2+}$ ions decreased to $4.63 \mathrm{mg} \mathrm{ml}^{-1}$. After the second production of 100 beads, the concentration of $\mathrm{Ca}^{2+}$ ions decreased to 


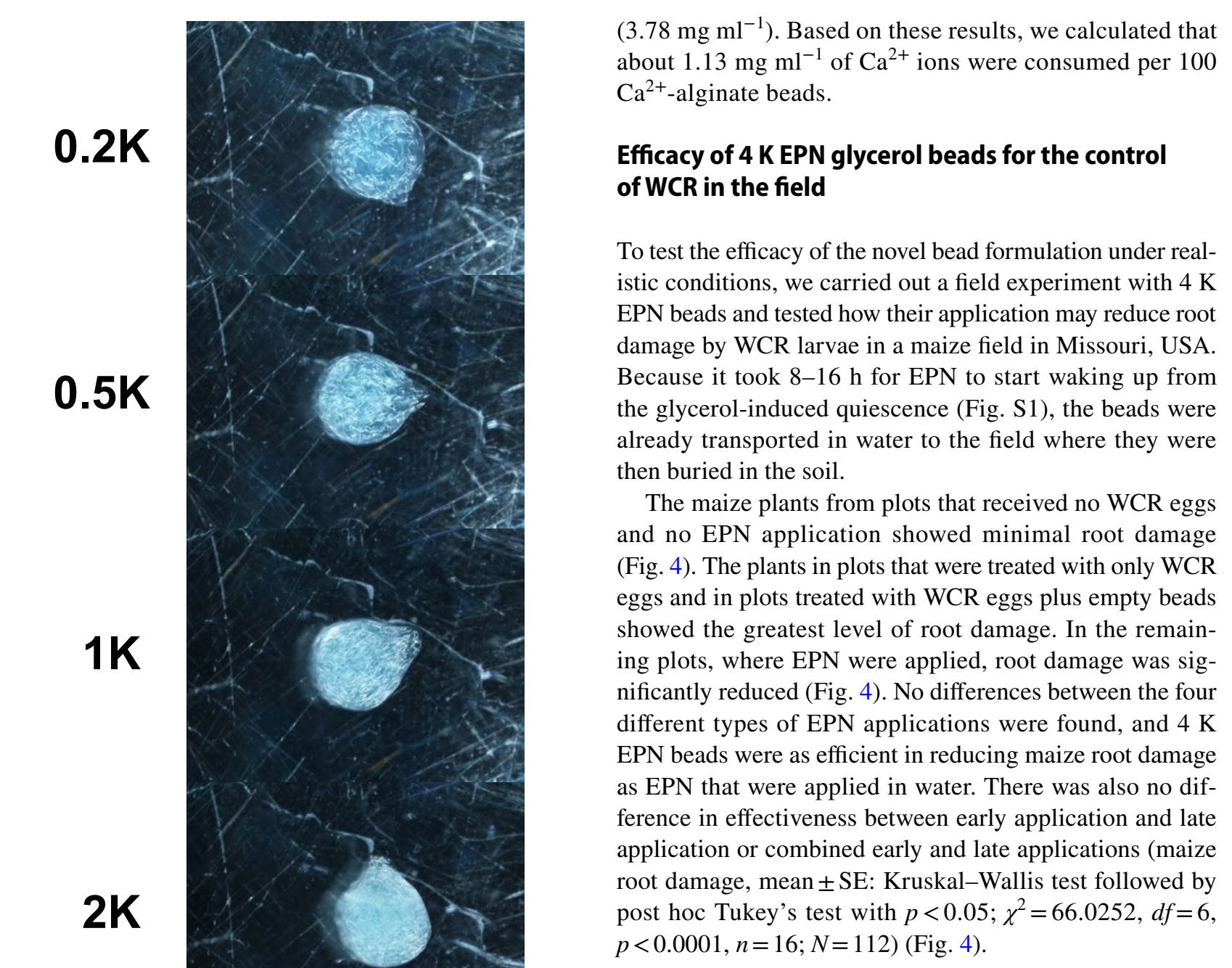

(3.78 $\mathrm{mg} \mathrm{ml}^{-1}$ ). Based on these results, we calculated that about $1.13 \mathrm{mg} \mathrm{ml}^{-1}$ of $\mathrm{Ca}^{2+}$ ions were consumed per 100 $\mathrm{Ca}^{2+}$-alginate beads.

\section{Efficacy of $4 \mathrm{~K}$ EPN glycerol beads for the control}

To test the efficacy of the novel bead formulation under realistic conditions, we carried out a field experiment with $4 \mathrm{~K}$ EPN beads and tested how their application may reduce root damage by WCR larvae in a maize field in Missouri, USA. Because it took 8-16 h for EPN to start waking up from the glycerol-induced quiescence (Fig. S1), the beads were already transported in water to the field where they were en buried in the soil.

The maize plants from plots that received no WCR eggs and no EPN application showed minimal root damage (Fig. 4). The plants in plots that were treated with only WCR eggs and in plots treated with WCR eggs plus empty beads showed the greatest level of root damage. In the remaining plots, where EPN were applied, root damage was significantly reduced (Fig. 4). No differences between the four different types of EPN applications were found, and $4 \mathrm{~K}$ PN beads were as efficient in reducing maize root damage ference in effectiveness between early application and late application or combined early and late applications (maize post hoc Tukey's test with $p<0.05 ; \chi^{2}=66.0252, d f=6$, $p<0.0001, n=16 ; N=112$ ) (Fig. 4).

\section{Discussion}

In this study, we developed mass-producible $\mathrm{Ca}^{2+}$-alginate EPN beads that can house and liberate as many as 4,000 EPN per $90-\mu l$ bead. EPN incorporated in these beads were stored without refrigeration in a state of glycerol-induced quiescence. It is known that that EPN can be conserved like this for at least 6 months without affecting infectivity (Chen and Glazer 2005). We also show in a field experiment that the application of the $4 \mathrm{~K} \mathrm{EPN}$ beads into the soil around maize plants was as efficient in protecting maize roots against rootworms as EPN applied in water.

In a previous study (Kim et al. 2015), we focused on the chemical and physical properties of $\mathrm{Ca}^{2+}$-alginate capsules (not beads), seeking conditions under which EPN are best retained in the formulation. We had improved the retainment of EPN inside these capsules by about $40 \%$. However, for an effective control of root pests, the release of EPN out of the formulation into the soil is as important as retaining them inside during storage. The initial capsule formulation was 
Table 1 The number of EPN that were incorporated into and emerged from glycerol- $\mathrm{Ca}^{2+}$ alginate beads and the survival rate of $\operatorname{EPN}(n=10)$

\begin{tabular}{|c|c|c|c|c|}
\hline \multirow[t]{2}{*}{ EPN beads } & \multicolumn{2}{|c|}{ Number of EPN per bead } & \multirow{2}{*}{$\begin{array}{l}\text { EPN release rate }(\%) \\
(\text { Mean } \pm \mathrm{SE})\end{array}$} & \multirow{2}{*}{$\begin{array}{l}\text { EPN survival } \\
\text { rate }(\%)^{* * *} \\
(\text { Mean } \pm \mathrm{SE})\end{array}$} \\
\hline & Incorporated $*$ & Released** $($ Mean \pm SE $)$ & & \\
\hline $0.2 \mathrm{~K}$ & 172 & $134.7 \pm 3.1$ & $78.3 \pm 1.8$ & $99.8 \pm 0.1$ \\
\hline $0.5 \mathrm{~K}$ & 430 & $265.4 \pm 9.9$ & $61.7 \pm 2.3$ & $99.8 \pm 0.1$ \\
\hline $1 \mathrm{~K}$ & 859 & $607.9 \pm 18.5$ & $70.8 \pm 2.2$ & $99.4 \pm 0.2$ \\
\hline $2 \mathrm{~K}$ & 1,718 & $1,483.8 \pm 25.4$ & $86.4 \pm 1.5$ & $98.6 \pm 0.3$ \\
\hline $4 \mathrm{~K}$ & 4,295 & $3,758.1 \pm 91.4$ & $87.5 \pm 2.1$ & $98.1 \pm 0.4$ \\
\hline
\end{tabular}

*The number of incorporated EPN per bead estimated from the mean volume of a droplet of EPN-containing glycerol-alginate solution $(85.9 \pm 0.7 \mu 1$, mean $\pm \mathrm{SE}, n=50)$. EPN-containing glycerol-alginate solution was prepared to have approximately 200,500,1,000, 2,000 and 4,000 EPN per $100 \mu \mathrm{l}$ and simply named $0.2 \mathrm{~K}, 0.5 \mathrm{~K}, 1 \mathrm{~K}, 2 \mathrm{~K}$ and $4 \mathrm{~K}$ EPN beads, respectively. **After 7 days of storage of EPN beads under the influence of $18 \%$ of glycerol, glycerol-induced EPN quiescence was broken by diluting out glycerol of beads with excess of water and the number of released EPN was individually counted. ***The number of live EPN divided by the number of all the escaped EPN

Table 2 Test groups assigned in the field experiment

\begin{tabular}{|c|c|c|c|c|c|}
\hline Test groups & Treatments & & WCR eggs & EPN & Beads \\
\hline No WCR / No EPN & Blank & & - & - & - \\
\hline WCR only & WCR eggs only & & + & - & - \\
\hline Empty beads & Bead control: $\mathrm{Ca}^{2+}$-alginate bead & ds without EPN & + & - & + \\
\hline EPN water & Application of EPN with water & & + & + & - \\
\hline \multirow[t]{3}{*}{ EPN beads } & Early & Application of $4 \mathrm{~K}$ EPN beads before WCR larvae hatched & + & + & + \\
\hline & Late & $\begin{array}{l}\text { Application of } 4 \mathrm{~K} \text { EPN beads during the active root her- } \\
\text { bivory by WCR }\end{array}$ & + & + & + \\
\hline & $\mathrm{E}+\mathrm{L}$ & Two-time application of $4 \mathrm{~K}$ EPN beads: Early + Late & + & + & + \\
\hline
\end{tabular}

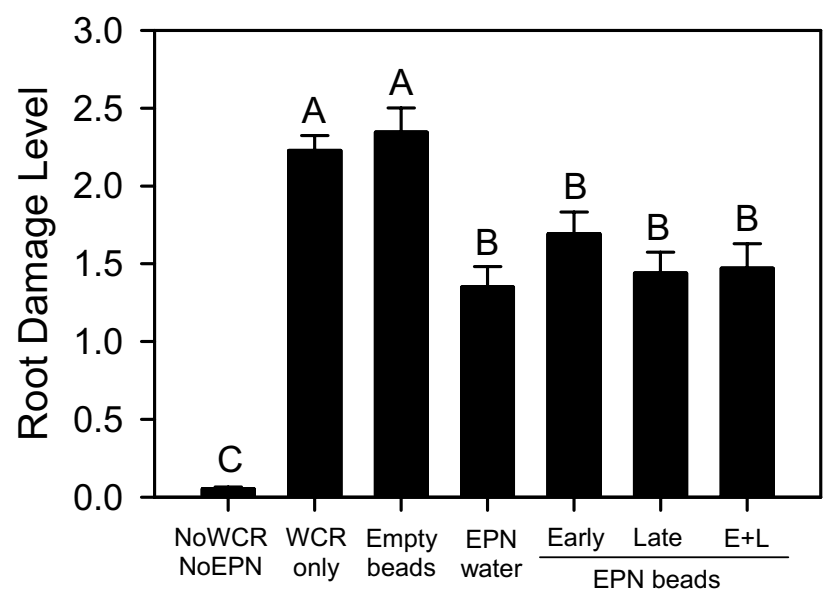

Fig. 4 Efficacy of EPN in protecting maize roots from WCR larvae in a field trial. Control plants (NoWCR, NoEPN) suffered significantly less damage than any other of the treatments. Plots with insect infestation but no EPN (WCR only and Empty beads) had the most damage, whereas EPN application (EPN water, Early/Late/Early + Late $(\mathrm{E}+\mathrm{L}) \mathrm{EPN}$ beads) suffered significantly less damage, whether the EPN were sprayed or applied in $4 \mathrm{~K}$ beads. EPN beads were formed with $0.5 \%$ sodium alginate and $2 \% \mathrm{CaCl}_{2} \cdot 2 \mathrm{H}_{2} \mathrm{O}$ solutions as described in the text. Bars represent SEM, and capital letters indicate statistical differences between treatments also problematic because it relied on dripping droplets of sodium alginate solution into $\mathrm{CaCl}_{2} \cdot 2 \mathrm{H}_{2} \mathrm{O}$ solution, whereby the capsule shell grows outward and the growing capsules readily stick to each other (Kim et al. 2015). Moreover, the concentration of alginate polymer in the sodium alginate solution decreases after production of a single capsule, requiring that it is continuously replaced with fresh alginate solution, which is expensive and time consuming.

To develop a formulation with prolonged retainment and controlled release of EPN, we adopted two new strategies. Firstly, we used glycerol to induce EPN quiescence. If they are not in a state of quiescence, EPN will continuously try to wiggle out of the capsule, depleting their energy resources and losing infectivity. In a dormant state, EPN will stay vigorous and infectious for a considerable time until quiescence is broken (Hiltpold et al. 2015; Jaffuel et al. 2015). Secondly, we used concentrations of sodium alginate and $\mathrm{CaCl}_{2} \cdot 2 \mathrm{H}_{2} \mathrm{O}$ that produce beads from which EPN can readily escape when quiescence is broken by adding water. After this, it takes about $8-16 \mathrm{~h}$ for EPN to recover. For the field experiment, we therefore placed $4 \mathrm{~K}$ EPN beads in water just before going out to the field. In the field, $4 \mathrm{~K}$ EPN beads were found 
to be as efficient in reducing WCR herbivory as EPN that were applied in water (Fig. 4).

The first-reported $\mathrm{Ca}^{2+}$-alginate EPN beads were produced with $2 \%$ sodium alginate and $100 \mathrm{mM}$ of $\mathrm{CaCl}_{2} \cdot 2 \mathrm{H}_{2} \mathrm{O}$ solutions (Kaya et al. 1987; Kaya and Nelsen 1985). According to our screening results, such a formulation would release only a limited number of EPN, whereas our beads with $0.5 \%$ sodium alginate and $2 \% \mathrm{CaCl}_{2} \cdot 2 \mathrm{H}_{2} \mathrm{O}$ $\left(27 \mathrm{mM}\right.$ of $\mathrm{Ca}^{2+}$ ions) allow the release of most of the embedded EPN. In previous studies, spontaneous escape of EPN out of $\mathrm{Ca}^{2+}$-alginate formulations was not considered (Hiltpold et al. 2012; Kim et al. 2015; Navon et al. 1998, 2002; Renn 1995). Instead, the authors adopted different strategies to liberate EPN. Kaya et al. (1987) used a citrate solution to dissolve $\mathrm{Ca}^{2+}$-alginate matrix, which could be useful to liberate EPN after storage in $\mathrm{Ca}^{2+}$-alginate beads (Chen and Glazer 2005), but not practical for the field application (Grewal 2002). Kaya et al. (1987) also introduced the elegant strategy of encapsulating a crop seed in each bead. The germinating seeds open up the beads, allowing EPN to be liberated. This approach, however, exposes the seeds to humidity, rapidly inducing germination, and thus making the beads not suitable for long-term storage. Lastly, alginate gels or capsules have also been spiked with feeding stimulants or attractants for target insects, such as yeast extract, sugar or fatty acids (Hiltpold et al. 2012; Navon et al. 1998, 2002). Navon et al. $(1998 ; 2002)$ used a gel disk formulation containing yeast extract, which they applied to the canopy of cotton plants infested with caterpillars. Hiltpold et al. (2012) incorporated several known attractants of WCR larvae into alginate capsules, which enhanced the effectiveness of the capsules in the field. Compared to these formulations, our beads should allow for long-term storage, for several months (Chen and Glazer 2005), without affecting EPN infectivity and they can be "planted" along with crop seeds, which would be far less labor intensive than conventional EPN application methods.

Also, the bead formulation allows for the encapsulation of large numbers of EPN. Quiescence induction was found to be essential to prevent the EPN from moving to the center during bead formation. When a droplet of sodium alginate solution is dropped into $\mathrm{CaCl}_{2} \cdot 2 \mathrm{H}_{2} \mathrm{O}$ solution, a $\mathrm{Ca}^{2+}$-alginate network starts to form at the boundary of the two solutions and this matrix grows inward. Non-dormant EPN move along to the center, but as shown in Figs. 2 and 3 , with quiescence induction, this movement could be prevented. We successfully encapsulated as many as 4,000 EPN per 5-mm diameter bead (Fig. 3). Interestingly, with these high numbers, EPN release rate was highest; after submergence in water, almost $90 \%$ made their way out of the beads. The better release from the most densely packed beads may be due to a looser matrix structure because a lower ratio of alginate molecules participating in the formation of the $\mathrm{Ca}^{2+}$-alginate network. With more EPN per bead, only a small number of EPN beads are needed to effectively control root pests within each root system.

Application of 4 K EPN beads only once early in the growing season was as efficient in protecting maize roots from WCR damage as the double application of free EPN in water. These results are of great practical importance because they imply that a one-time application of $4 \mathrm{~K}$ EPN beads along with planting maize seeds may be enough to protect maize roots from WCR damage throughout the season.

Georgis et al. (2006) list a number of requirements that are important for commercialization of EPN. These include good control efficacy against the target pest under the field conditions, low production cost, ease of handling and transportation, and long shelf-life. Our version of $\mathrm{Ca}^{2+}$-alginate beads meets these criteria, but with a couple of minor issues still to be considered. First, different species and strains of EPN show different efficacies in killing a given insect pest, which may indicate limitations to their respective host range (Peters 1996). We used H. bacteriophora that has been reported to be effective against WCR larvae (Kurtz et al. 2009; Toepfer et al. 2005, 2008). Other species may require fine adjustments to the conditions required for successful encapsulation. Second, in the field study carried out in this study, the beads were transferred from the laboratory to the maize field in water to quickly break glycerol-induced quiescence. For future application, it may be more practical to directly bury the beads. In that case, the breaking of quiescence will mainly depend on soil water content. Ideally, the formulation would be adjusted to ensure a continuous release of EPN into the rhizosphere beyond the moment WCR larvae hatch and start to inflict damage to the roots. Irrigation timing may be adapted to facilitate EPN release at the right moment. On the other hand, low soil water content may facilitate a continuous release of EPN into the rhizosphere throughout growing season.

In summary, in this study we present a new formulation of $\mathrm{Ca}^{2+}$-alginate beads that allow complete retainment of several thousands of EPN per 4-5-mm diameter bead. During storage, glycerol-induced quiescence keeps the EPN inside the beads. Quiescence can be readily broken by adding water just before soil application. In a field trial, the beads were as effective in protecting maize roots from WCR larvae as EPN that were applied in a water solution. Different from previously reported alginate-based EPN formulations, the $\mathrm{Ca}^{2+}$-alginate EPN beads are expected to be suitable for mass-production and for long-term storage (at least for 6 months), and can, with some modification, be directly applied with the seeds during sowing. Further investigation 
into the dynamics of EPN release from the beads under a variety of growing conditions is warranted.

Supplementary information The online version contains supplementary material available at https://doi.org/10.1007/s10340-021-01349-4.

Acknowledgements This work was supported by a grant from the Swiss National Science Foundation (Grant No. 51NF40-144621).

Author contributions JK, IH and TCJT conceived and designed research. JK, GJ, IS and BEH conducted experiments. JK and GJ analyzed data. JK and TCJT wrote the manuscript. All authors read and approved the manuscript.

Funding Open Access funding provided by Université de Neuchâtel.. Swiss National Science Foundation (Grant No. 51NF40-144621).

Data availability All relevant data are included in the manuscript.

\section{Compliance with ethical standards}

Conflicts of interest We declare no conflict of interest.

Consent to participate All authors agree to be listed as being part of the study.

Consent for publication All authors agree to the publication of the submitted manuscript.

Open Access This article is licensed under a Creative Commons Attribution 4.0 International License, which permits use, sharing, adaptation, distribution and reproduction in any medium or format, as long as you give appropriate credit to the original author(s) and the source, provide a link to the Creative Commons licence, and indicate if changes were made. The images or other third party material in this article are included in the article's Creative Commons licence, unless indicated otherwise in a credit line to the material. If material is not included in the article's Creative Commons licence and your intended use is not permitted by statutory regulation or exceeds the permitted use, you will need to obtain permission directly from the copyright holder. To view a copy of this licence, visit http://creativecommons.org/licenses/by/4.0/.

\section{References}

Bashan Y (1998) Inoculants of plant growth-promoting bacteria for use in agriculture. Biotechnol Adv 16:729-770. https://doi. org/10.1016/S0734-9750(98)00003-2

Bathon H (1996) Impact of entomopathogenic nematodes on nontarget hosts. Biocontrol Sci Technol 6:421-434. https://doi. org/10.1080/09583159631398

Chen S, Glazer I (2005) A novel method for long-term storage of the entomopathogenic nematode Steinernema feltiae at room temperature. Biol Control 32:104-110. https://doi.org/10.1016/j.bioco ntrol.2004.08.006

Chiang HC, French LK, Rasmussen DE (1980) Quantitative relationship between western corn rootworm population and corn yield. J Econ Entomol 73:665-666. https://doi.org/10.1093/jee/73.5.665

Cruz-Martínez H, Ruiz-Vega J, Matadamas-Ortíz PT, Cortés-Martínez CI, Rosas-Diaz J (2017) Formulation of entomopathogenic nematodes for crop pest control - a review. Plant Protect Sci 53:15-24

Del Valle EE, Dolinski C, Souza RM (2008) Dispersal of Heterorhabditis baujardi LPP7 (Nematoda: Rhabditida) applied to the soil as infected host cadavers. Int J Pest Manage 54:115-122. https:// doi.org/10.1080/09670870701660579

Deol YS, Jagdale GB, Cañas L, Grewal PS (2011) Delivery of entomopathogenic nematodes directly through commercial growing media via the inclusion of infected host cadavers: a NOVEL approach. Biol Control 58:60-67. https://doi.org/10.1016/j.bioco ntrol.2011.03.002

Donati I, Holtan S, Mørch YA, Borgogna M, Dentini M (2005) New hypothesis on the role of alternating sequences in calcium-alginate gels. Biomacromol 6:1031-1040. https://doi.org/10.1021/ bm049306e

Dong Q-Y, Chen M-Y, Xin Y, Qin X-Y, Cheng Z, Shi L-E, Tang Z-X (2013) Alginate-based and protein-based materials for probiotics encapsulation: a review. Int J Food Sci Tech 48:1339-1351. https ://doi.org/10.1111/ijfs.12078

Gaugler R, Lewis E, Stuart RJ (1997) Ecology in the service of biological control: the case of entomopathogenic nematodes. Oecologia 109:483-489. https://doi.org/10.1007/s004420050108

Georgis R et al (2006) Successes and failures in the use of parasitic nematodes for pest control. Biol Control 38:103-123. https://doi. org/10.1016/j.biocontrol.2005.11.005

Godfrey LD, Meinke LJ, Wright RJ (1993) Vegetative and reproductive biomass accumulation in field com: response to root Injury by western com rootworm (Coleoptera: Chrysomelidae). J Econ Entomol 86:1557-1573. https://doi.org/10.1093/jee/86.5.1557

Gray ME, Sappington TW, Miller NJ, Moeser J, Bohn MO (2009) Adaptation and invasiveness of western corn rootworm: intensifying research on a worsening pest. Annu Rev Entomol 54:303-321. https://doi.org/10.1146/annurev.ento.54.110807.090434

Grewal PS (2000a) Anhydrobiotic potential and long-term storage of entomopathogenic nematodes (Rhabditida: Steinernematidae). Int J Parasitol 30:995-1000. https://doi.org/10.1016/s0020 -7519(00)00080-1

Grewal PS (2000b) Enhanced ambient storage stability of an entomopathogenic nematode through anhydrobiosis. Pest Manage Sci 56:401-406. https://doi.org/10.1002/(sici)1526-4998(20000 5)56:5\%3c401::Aid-ps137\%3e3.0.Co;2-4

Grewal PS (2002) Formulation and application technology. In: Gaugler R (ed) Entomopathogenic nematology. CABI Publishing, Wallingford, UK, pp 265-287

Hiltpold I, Hibbard BE, French BW, Turlings TCJ (2012) Capsules containing entomopathogenic nematodes as a Trojan horse approach to control the western corn rootworm. Plant Soil 358:11-25. https ://doi.org/10.1007/S11104-012-1253-0

Hiltpold I, Jaffuel G, Turlings TCJ (2015) The dual effects of rootcap exudates on nematodes: from quiescence in plant-parasitic nematodes to frenzy in entomopathogenic nematodes. J Exp Bot 66:603-611. https://doi.org/10.1093/jxb/eru345

Hoffman AS (2012) Hydrogels for biomedical applications. Adv Drug Del Rev 64:18-23. https://doi.org/10.1016/j.addr.2012.09.010

Imperiali N et al. (2017) Combined field inoculations of Pseudomonas bacteria, arbuscular mycorrhizal fungi, and entomopathogenic nematodes and their effects on wheat performance. Front Plant Sci 8:1809 https://doi.org/10.3389/fpls.2017.01809

Jaffuel G, Hiltpold I, Turlings TCJ (2015) Highly potent extracts from pea (Pisum sativum) and maize (Zea mays) roots can be used to induce quiescence in entomopathogenic nematodes. J Chem Ecol 41:793-800. https://doi.org/10.1007/s10886-015-0623-5

Jansson RK, Lecrone SH, Gaugler R (1993) Field efficacy and persistence of entomopathogenic nematodes (Rhabditida: Steinernematidae, Heterorhabditidae) for control of sweetpotato weevil 
(Coleoptera: Apionidae) in Southern Florida. J Econ Entomol 86:1055-1063. https://doi.org/10.1093/jee/86.4.1055

John RP, Tyagi RD, Brar SK, Surampalli RY, Prévost D (2011) Bioencapsulation of microbial cells for targeted agricultural delivery. Crit Rev Biotechnol 31:211-226. https://doi.org/10.3109/07388 551.2010 .513327

Kary NE, Chahardoli S, Mohammadi D, Dillon AB (2017) Effect of temperature, time and glycerol concentration on the dehydration and rehydration process of Steinernema carpocapsae and $\mathrm{S}$ feltiae in alginate granule formulation. Nematology 19(2):225-235

Kary NE, Chahardoli S, Mohammadi D, Dillon AB (2018) Effects of abiotic factors on the osmotic response of alginate-formulated entomopathogenic nematode, Heterorhabditis bacteriophora(Nematoda: Rhabditida). Biocontrol Sci Tech 28(7):688-701. https://doi.org/10.1080/09583157.2018.1479731

Kaya HK, Nelsen CE (1985) Encapsulation of Steinernematid and Heterorhabditid nematodes with calcium alginate: a new approach for insect control and other applications. Environ Entomol 14:572574. https://doi.org/10.1093/ee/14.5.572

Kaya HK, Mannion CM, Burlando TM, Nelsen CE (1987) Escape of Steinernema feltiae from alginate capsules containing tomato seeds. J Nematol 19:287-291

Kim J, Jaffuel G, Turlings TJ (2015) Enhanced alginate capsule properties as a formulation of entomopathogenic nematodes. BioControl 60:1-9. https://doi.org/10.1007/s10526-014-9638-Z

King AH (1982) Brown seaweed extracts (alginates). In: Glicksman M (ed) Food hydrocolloids. CRC Press, Boca Raton, USA, pp $115-188$

Koppenhöfer AM (2007) Nematodes. In: Lacey LA, Kaya HK (eds.) Field Manual of Techniques in Invertebrate Pathology: Application and Evaluation of Pathogens for Control of Insects and other Invertebrate Pests. Springer Netherlands, Dordrecht, pp 249-264, https://doi.org/10.1007/978-1-4020-5933-9_11

Kurtz B, Toepfer S, Ehlers R-U, Kuhlmann U (2007) Assessment of establishment and persistence of entomopathogenic nematodes for biological control of western corn rootworm. J Appl Entomol 131:420-425. https://doi.org/10.1111/j.1439-0418.2007.01202.x

Kurtz B, Hiltpold I, Turlings TCJ, Kuhlmann U, Toepfer S (2009) Comparative susceptibility of larval instars and pupae of the western corn rootworm to infection by three entomopathogenic nematodes. Biocontrol 54:255. https://doi.org/10.1007/s1052 6-008-9156-y

Lewis EE, Campbell J, Griffin C, Kaya H, Peters A (2006) Behavioral ecology of entomopathogenic nematodes. Biol Control 38:66-79. https://doi.org/10.1016/j.biocontrol.2005.11.007

Matadamas-Ortiz PT, Ruiz-Vega J, Vazquez-Feijoo JA, Cruz-Martínez H, Cortés-Martínez CI (2014) Mechanical production of pellets for the application of entomopathogenic nematodes: factors that determine survival time of Steinernema glaseri. Biocontrol Sci Technol 24:145-157. https://doi.org/10.1080/09583 157.2013.852161

Navon A, Keren S, Salame L, Glazer I (1998) An edible-to-insects calcium alginate gel as a carrier for entomopathogenic nematodes. Biocontrol Sci Technol 8:429-437. https://doi.org/10.1080/09583 159830225

Navon A, Nagalakshmi VK, Levski S, Salame L, Glazer I (2002) Effectiveness of entomopathogenic nematodes in an alginate gel formulation against lepidopterous pests. Biocontrol Sci Technol 12:737-746. https://doi.org/10.1080/0958315021000039914

Oleson JD, Park Y-L, Nowatzki TM, Tollefson JJ (2005) Node-injury scale to evaluate root injury by corn rootworms (Coleoptera: Chrysomelidae). J Econ Entomol 98:1-8. https://doi.org/10.1093/ jee/98.1.1
Peters A (1996) The natural host range of Steinernema and Heterorhabditis spp. and their impact on insect populations. Biocontrol Sci Technol 6:389-402. https://doi.org/10.1080/09583159631361

Renn N (1995) Mortality of immature houseflies (Musca domestica L.) in artificial diet and chicken manure after exposure to encapsulated entomopathogenic nematodes (Rhabditida: Steinernematidae, Heterorhabditidae). Biocontrol Sci Technol 5:349-360. https ://doi.org/10.1080/09583159550039792

Rovesti L, Deseö KV (1990) Compatibility of chemical pesticides with the entomopathogenic nematodes, Steinernema carpocapsae Weiser and S. feltiae Filipjev (Nematoda: Steinernematidae). Nematologica 36:237-245

Sabra W, Zeng AP, Lünsdorf H, Deckwer WD (2000) Effect of oxygen on formation and structure of Azotobacter vinelandii alginate and its role in protecting nitrogenase. Appl Environ Microbiol 66:4037-4044. https://doi.org/10.1128/aem.66.9.4037-4044.2000

Schoebitz M, López MD, Roldán A (2013) Bioencapsulation of microbial inoculants for better soil-plant fertilization. Rev Agron Sustain Dev 33:751-765. https://doi.org/10.1007/s13593-013-0142-0

Shapiro-Ilan DI, Jackson M, Reilly CC, Hotchkiss MW (2004) Effects of combining an entomopathogenic fungi or bacterium with entomopathogenic nematodes on mortality of Curculio caryae (Coleoptera: Curculionidae). Biol Control 30:119-126. https:// doi.org/10.1016/j.biocontrol.2003.09.014

Shapiro-Ilan DI, Gouge DH, Piggott SJ, Fife JP (2006) Application technology and environmental considerations for use of entomopathogenic nematodes in biological control. Biol Control 38:124-133. https://doi.org/10.1016/j.biocontrol.2005.09.005

Shapiro-Ilan DI, Han R, Dolinksi C (2012) Entomopathogenic nematode production and application technology. J Nematol 44:206-217

Toepfer S, Gueldenzoph C, Ehlers RU, Kuhlmann U (2005) Screening of entomopathogenic nematodes for virulence against the invasive western corn rootworm, Diabrotica virgifera virgifera (Coleoptera: Chrysomelidae) in Europe. Bull Entomol Res 95:473-482. https://doi.org/10.1079/BER2005379

Toepfer S, Peters A, Ehlers R-U, Kuhlmann U (2008) Comparative assessment of the efficacy of entomopathogenic nematode species at reducing western corn rootworm larvae and root damage in maize. J Appl Entomol 132:337-348. https://doi.org/10.111 1/j.1439-0418.2008.01274.x

Tønnesen HH, Karlsen J (2002) Alginate in drug delivery systems. Drug Dev Ind Pharm 28:621-630. https://doi.org/10.1081/DDC120003853

Vemmer M, Patel AV (2013) Review of encapsulation methods suitable for microbial biological control agents. Biol Control 67:380-389. https://doi.org/10.1016/j.biocontrol.2013.09.003

White GF (1927) A method for obtaining infective nematode larvae from cultures. Science 66:302. https://doi.org/10.1126/scien ce.66.1709.302-a

Zhu H, Grewal PS, Reding ME (2011) Development of a desiccated cadaver delivery system to apply entomopathogenic nematodes for control of soil pests. Appl Eng Agric 27:317-324. https://doi. org/10.13031/2013.37065

Publisher's Note Springer Nature remains neutral with regard to jurisdictional claims in published maps and institutional affiliations. 